\title{
BEBERAPA ASPEK BIOLOGI KEBOGERANG (Mystus nigriceps) DI SUNGAI CITARUM, JAWA BARAT
}

\author{
Biological aspects of kebogerang (Mystus nigriceps) in Citarum river, West Java
}

\author{
Makri $^{1 *}$, Rangga Bayu Kusuma Haris ${ }^{2}$, Rahma Mulyani ${ }^{3}$ \\ ${ }^{1}$ Balai Riset Perikanan Perairan Umum dan Penyuluhan Perikanan \\ ${ }^{2}$ Politeknik Kelautan dan Perikanan Dumai \\ ${ }^{3}$ Program Studi Budidaya Ikan Fakultas Perikanan Universitas PGRI Palembang \\ * Corresponding author : Makri.brppu@gmail.com
}

\begin{abstract}
ABSTRAK
Jenis ikan asli yang masih bertahan hidup di Sungai Citarum sebanyak 26 jenis dengan distribusi yang berbeda untuk setiap kawasan. Salah satu ikan asli di Sungai Citarum berasal dari famili Bagridae yaitu ikan kebogerang (Mystus nigriceps). Tujuan dari penelitian ini adalah untuk mengetahui biologi reproduksi ikan kebogerang (Mystus nigriceps) di Sungai Citarum. Metode analisis yang digunakan adalah Indeks of Preponderance dan Analisis lndeks Kematangan Gonad. Analisis fekunditas dihitung berdasarkan metode gravimetrik. Penelitian ini dilakukan pada bulan Agustus dan September 2020. Alat tangkap yang digunakan adalah gill-net dengan ukuran mata jaring 1; 1,5, 2; 2,5 inci dan jala/kincrik (cashnet). Ikan sampel diukur panjang beratnya, diambil isi perut dan gonadnya kemudian diawetkan dengan formalin 4\%; selanjutnya diamati di bawah mikroskop. Hasil yang didapat menunjukkan bahwa ikan kebogerang merupakan ikan omnivora yang memanfaatkan serangga, larva serangga sebagai makanan utama. Dengan Ukuran pertama kali matang gonad yaitu 14,5 cm dan memiliki fekunditas berkisar antara 3.475 - 37.611 butir telur.
\end{abstract}

Kata kunci : Kebogerang (Mystus nigriceps), kebiasaan makanan, fekunditas

\begin{abstract}
There are 26 species of endemic fishes that still survive in the Citarum River with different distributions for each area. One of the endemic fish in the Citarum River form Bagridae family of the kebogerang fish (Mystus nigriceps). The purpose of this study was to determine the reproductive biology of Kebogerang fish (Mystus nigriceps) in the Citarum River. The analysis method used was the Index of Preponderance and Gonad Maturity Index Analysis. Fecundity analysis was calculated based on the gravimetric method. This research was conducted in August and September 2020. The fishing gear used was the gill-net with a mesh size of 1; 1,5, 2; 2.5 inches and net / kincrik (cashnet). The sample fish were measured in length and weight, taken the stomach contents and gonads then preserved with 4\% formalin; further observed under a microscope. The results obtained indicate that the fish kebogerang is an omnivorous fish that uses insects, insect larvae as the main food. With the size for the first time to mature gonads is $14.5 \mathrm{~cm}$ and has fecundities ranging from 3,475 37,611 grains.
\end{abstract}

Keywords : Kebogerang (Mystus nigriceps), food habits, fecundity 


\section{PENDAHULUAN}

Sungai Citarum merupakan sungai terpanjang dan terbesar di Jawa Barat dengan panjang sungai sebesar $297 \mathrm{~km}$ dan luas daerah aliran sungai sebesar 6614 $\mathrm{km}^{2}$. Berhulu di Situ Cisanti yang terletak di Gunung Wayang, Kabupaten Bandung dan berakhir di Laut Jawa yang terletak di Muara Gembong, Kabupaten Bekasi. Sejak tahun 1965 di aliran Sungai Citarum telah dibangun tiga buah waduk besar, yaitu Waduk Jatiluhur (Djuanda) di bagian hilir, Waduk Cirata bagian tengah dan Waduk Saguling bagian hulu (Kartamihardja, 2019). Namun sejak beberapa tahun ini sungai Citarum dikenal sungai yang sangat tercemar, bahkan tercemar nomor dua di dunia. Oleh karena itu oleh pemerintah dijadikan sebagai prioritas untuk dikembalikan menjadi lingkungan atau ekosistem perairan yang berdaya guna, menjadi isu nasional bahkan internasional. Saat ini program Citarum harum sudah mulai berhasil memperlihatkan kondisi perairan yang sudah baik. Aktifitas perikanan tangkap sudah terlihat, restocking sebagai pemacu produktifitas perairan sudah mulai memperlihatkan hasil.

Jenis ikan asli yang hidup di Sungai Citarum hampir seluruhnya termasuk ikan sungai (riverine species). Di Sungai Citarum tersebut tercatat sebanyak 34 jenis ikan asli dan 11 jenis ikan asing. Jenis ikan asli yang masih bertahan hidup di Sungai Citarum sebanyak 26 jenis dengan distribusi yang berbeda untuk setiap kawasan. Salah satu ikan asli di Sungai Citarum berasal dari famili Bagridae yaitu ikan kebogerang (Mystus nigriceps). Ikan ini hidup di dasar perairan (ikan demersal) sungai, danau, rawa, dan waduk (Gaffar \& Utomo, 1991; Kartamihardja, 2019).

Setiap spesies ikan memiliki strategi yang berbeda dalam mempertahankan kelangsungan hidupnya, bahkan ikan dalam spesies yang sama juga memiliki strategi yang berbeda bila berada pada kondisi lingkungan dan letak geografis yang berbeda. Informasi tentang daur reproduksi ikan dan faktor-faktor lingkungan yang mempengaruhinya merupakan hal yang penting dalam biologi perikanan (Tomkiewicz et al., 2003). Hal inilah yang mendasari dilakukannya penelitian mengenai biologi reproduksi ikan kebogerang (Mystus nigriceps) di Sungai Citarum.

\section{BAHAN DAN METODE}

Penelitian dilakukan pada bulan Agustus dan September 2019. Ikan Kebogerang mendominasi hasil tangkapan nelayan yang menggunakan alat tangkap gill-net dengan ukuran mata jaring $1 ; 1,5$, 2; 2,5 inchi dan jala/kincrik (cashnet). Lokasi sampling sungai Citarum hulu khususnya segmen desa Mandawangi yaitu pertemuan muara anak sungai Citarum, yaitu sungai Cihujung dan Citarum. Ikan sampel diukur panjang beratnya, diambil isi perut dan gonadnya kemudian diawetkan dengan formalin $4 \%$; selanjutnya diamati di bawah mikroskop.

\section{Analisis Makanan dan Kebiasaan Makan}

Jenis makanan ikan diamati dengan melihat isi perut ikan. Dihitung untuk setiap contoh ikan. Analisis yang digunakan dalam menghitung kebiasaan pakan ikan menggunakan rumus Indeks of Preponderance dari Natarajan dan Jhingran dalam Effendie (1979) yaitu:

Keterangan:

$$
\mathrm{Ii}=\frac{\mathrm{V}_{\mathrm{i}} \times \mathrm{O}_{\mathrm{i}}}{\sum\left(\mathrm{V}_{\mathrm{i}} \times \mathrm{O}_{\mathrm{i}}\right)} \times 100 \%
$$

$\mathrm{Ii}=$ Indeks of Preponderance

$\mathrm{Vi}=$ Presentase volume satu macam makanan

Oi $=$ Presentase frekuensi kejadian satu macam makanan

Untuk mengidentifikasi jenis makanan digunakan buku identifikasi dari 
Edmonson (1959), Needham \& Needham (1963).

\section{Analisis Reproduksi Ikan}

Tingkat kematangan gonad merupakan modifikasi dari Cassie dalam Effendie dan Sjafei (1976) yang diklasifikasikan menjadi 5 (lima) tingkatan. Pengamatan diameter telur dilakukan dengan menggunakan mikroskop yang dilengkapi dengan milimeter okuler; penyajian data potensi reproduksi mengenai analisis fekunditas dihitung berdasarkan metode gravimetrik dalam Nikolsky (1963) yaitu :

$$
\mathbf{X} / \mathbf{x}=\mathbf{B} / \mathbf{b}
$$

Keterangan:

$\mathrm{X}=$ Jumlah telur dalam gonad yang akan dicari

$\mathrm{x}=$ Jumlah telur sebagian keril gonad (gram)

$\mathrm{B}=$ Berat seluruh gonad (gram)

$\mathrm{b}=$ Berat sebagian gonad (gram)

Indeks kematangan gonad (IKG) bertujuan untuk mengetahui tingkat kematangan gonad suatu ikan. IKG ini di hitung melalui pembagi berat gonad ikan dengan bobot tubuh ikan Effendie (1979), dengan rumus sebagai berikut:

$$
\begin{aligned}
& \text { IKG }=\mathbf{B g} / \mathbf{B t} \mathbf{X} \mathbf{1 0 0 \%} \\
\mathrm{IKG}= & \text { Indeks Kematangan Gonad } \\
\mathrm{Bg}= & \text { Berat gonad }(\text { gram }) \\
\mathrm{Bt}= & \text { Berat tubuh }(\text { gram }) \\
& \text { Untuk Tingkat Kematangan } \\
& \text { Gonad I tidak dihitung IKG-nya }
\end{aligned}
$$

Penentuan ukuran pertama kali matang gonad dengan menggunakan metode Sperman Karber (Udapa 1986, dalam Musbir et al., 2006). Kriteria matang gonad adalah pada TKG III, IV dan V. Adapun rumusnya adalah sebagai berikut:

$$
\log M=X_{k}+\frac{X}{2}-\left(x \sum P_{i}\right)
$$

Keterangan :

$\mathrm{Xk}=$ Logaritma nilai tengah pada saat ikan matang gonad $100 \%$

$\mathrm{X}=$ Selisih logaritma nilai tengah kelas

$\mathrm{Xi}=$ Logaritma nilai tengah kelas

$\mathrm{pi}=\mathrm{ri} / \mathrm{ni}$

ri = Jumlah ikan matang gonad pada kelas ke i

ni $=$ Jumlah ikan pada kelas ke $\mathrm{i}$

$\mathrm{Qi}=\mathrm{i}-\mathrm{pi}$

\section{HASIL DAN PEMBAHASAN}

Ikan kebogerang (Mystus nigriceps) termasuk dalam famili Bagridae. Badan ikan kebogerang memiliki bentuk gilik, mulut yang melengkung, tidak bersisik, mempunyai sirip dada yang kuat dan bergerigi, serta sirip lemak yang besar. Pada umumnya kumis rahang ikan kebogerang sangat panjang (Kottelat et al., 1993). Ikan sampel didapatkan sebanyak 47 ekor pada bulan Agustus dan 71 ekor pada bulan September.

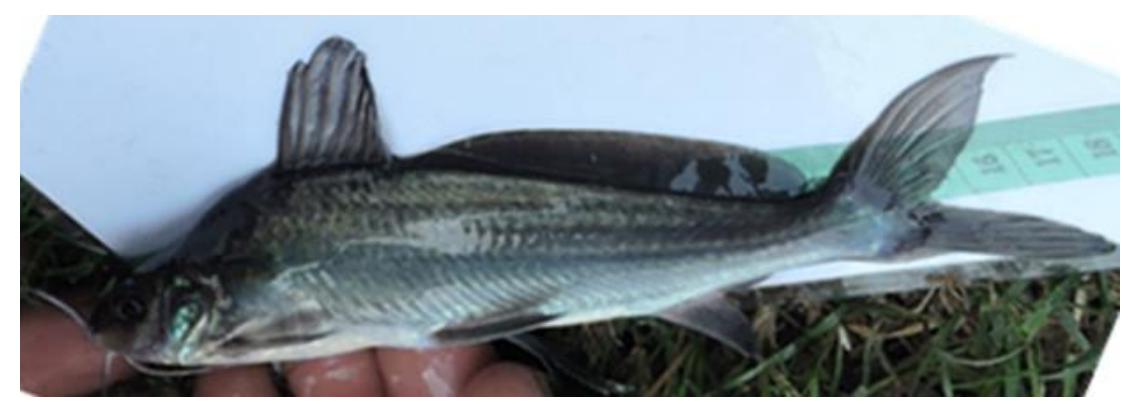

Gambar 1. Ikan Kebogerang (Mystus nigriceps) 


\section{Kebiasaan Makan}

Salah satu faktor yang menentukan bagi pertumbuhan dan populasi ikan ialah makanan. Pada satu perairan kalau terjadi perubahan lingkungan yang menyebabkan perubahan persediaan makanan, maka ikan akan merubah kebiasaan makanannya. Dengan mengetahui kebiasaan makanan ikan dapat dilihat hubungan ekologi diantara organisme di perairan itu (Effendie, 1997). Ikan dapat beruaya untuk mencari makan untuk melanjutkan pertumbuhan tubuhnya dan pertumbuhan populasinya.

Makanan ikan dibagi dalam 3 (tiga) tingkatan yaitu makanan utama adalah jenis makanan yang mempunyai indeks of preponderance (IP) $\geq 25 \%$; makanan pelengkap adalah jenis makanan yang mempunyai nilai IP antara 4-25\%, dan makanan tambahan adalah jenis pakan yang mempunyai IP kurang dari $4 \%$ (Hariyadi, 1983).

Index propederance ikan kebogerang tertera pada Gambar 2. Pada bulan Agustus, dan September komposisi kebiasaan makan ikan yang tertangkap didominasi oleh serangga dan larvanya, yaitu sebanyak $45 \%$ (Agustus) dan $33 \%$ pada bulan September. Kebiasaan makan Ikan kebogerang sungai Citarum hulu hampir sama dengan ikan Ingir-ingir (Mystus nigriceps) di sungai Tarai Kampar Provinsi Riau, yaitu $71 \%$ isekta (Colia et al., 2019).

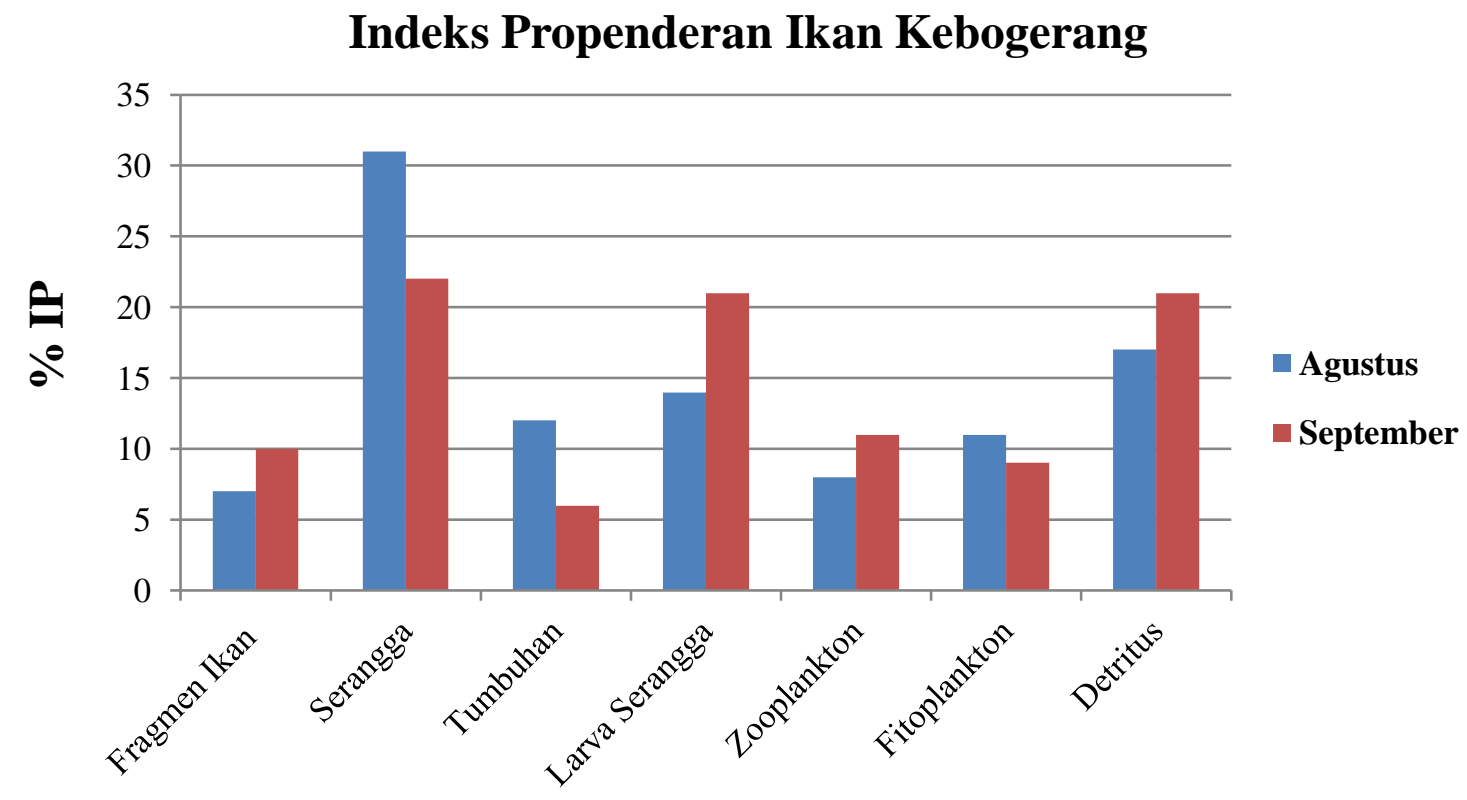

Gambar 2. Kebiasaan makanan ikan kebogerang (Mystus nigriceps) selama pengamatan

\section{Reproduksi Ikan}

Kematangan gonad ialah suatu tahap tertentu dari perkembangan gonad sebelum dan sesudah ikan tersebut melakukan pemijahan. Tingkat kematangan gonad yang digunakan merupakan modifikasi dari Cassie dalam Effendie dan Sjafei (1976) (Tabel 1): 
Tabel 1. Klasifikasi tingkatan kematangan gonad

\begin{tabular}{|c|c|c|}
\hline $\begin{array}{c}\text { Tingkat } \\
\text { Kematangan }\end{array}$ & Jantan & Betina \\
\hline I & $\begin{array}{l}\text { Testes seperti benang, lebih } \\
\text { pendek (terbatas) dan terlihat } \\
\text { ujungnya dirongga tubuh warna } \\
\text { jernih. }\end{array}$ & $\begin{array}{l}\text { Ovari seperti benang, panjang } \\
\text { sampai kedepan rongga tubuh. } \\
\text { Warna jernih. Permukaan licin. }\end{array}$ \\
\hline II & $\begin{array}{l}\text { Ukuran testes lebih besar. } \\
\text { Warna putih seperti susu. } \\
\text { Bentuk lebih jelas dari pada } \\
\text { tingkat I. }\end{array}$ & $\begin{array}{l}\text { Ukuran ovari lebih besar. Warna } \\
\text { lebih gelap kekuning-kuningan. } \\
\text { Telur belum telihat jelas dengan } \\
\text { mata. }\end{array}$ \\
\hline III & $\begin{array}{l}\text { Permukaan testes tampak } \\
\text { bergerigi warna makin putih, } \\
\text { testes makin besar. Dalam } \\
\text { keadaan diawet mudah putus. }\end{array}$ & $\begin{array}{l}\text { Ovari berwarna kuning. Secara } \\
\text { morfologi telur mulai kelihatan } \\
\text { butirnya dengan mata. }\end{array}$ \\
\hline IV & $\begin{array}{l}\text { Seperti pada tingkat Ill tampak } \\
\text { lebih jelas. Testes semakin } \\
\text { pejal. }\end{array}$ & $\begin{array}{l}\text { Ovari makin besar, telur } \\
\text { berwarna kuning, mudah } \\
\text { dipisahkan. Butir minyak tidak } \\
\text { tampak, mengisi } 1 / 2-2 / 3 \text { rongga } \\
\text { perut, usus terdesak }\end{array}$ \\
\hline V & $\begin{array}{l}\text { Testes bagian belakang kempis } \\
\text { dan di bagian dekat pelepasan } \\
\text { masih berisi. }\end{array}$ & $\begin{array}{l}\text { Ovari berkerut, dinding tebal, } \\
\text { butir telur sisa terdapat didekat } \\
\text { pelepasan. Banyak telur seperti } \\
\text { pada tingkat II. }\end{array}$ \\
\hline
\end{tabular}

Hasil pengamatan fekunditas ikan kebogerang terhadap ikan sampel menunjukkan diameter telur $0,12-1,6$ $\mathrm{mm}$, dan 0,2950 - 0,6325 mm, dengan fekunditas berkisar 3.475-37.611 butir untuk ukuran ikan antara 14,5-26,5 cm hampir sama dengan fekunditas ikan Ingir-ingir (Mystus nigriceps) 4.64434.938 butir, diameter 0,4-0,7 mm (Nataliska et al., 2019). Berdasarkan TKG dan sebaran diameter telur tersebut, ikan kebogerang di Sungai Citarum hulu ini dapat diduga memijah berapakali dalam satu tahun.

\section{Ukuran Pertama Kali Matang Gonad}

Ukuran pertama kali matang gonad ikan kebogerang di hulu sungai Citarum didapatkan pada ukuran $14,5 \mathrm{~cm}$ pada bulan Agustus dan $15 \mathrm{~cm}$ pada bulan September. Ikan kebogerang sungai Citarum lebih cepat matang gonad jika dibandingkan dengan yang dari sungai Klawing Purbalingga Jawa tengah. Di sini ikan kebogerang atau ikan Senggaringan (Mystus nigriceps) mempunyai ukuran pertama kali matang gonad $148.9010 \mathrm{~mm}$ (Heltonika et al., 2016). Hal ini diduga karena ikan kebogerang (Mystus nigriceps) mengalami tekanan lingkungan perairan tercemar sehingga matang gonad pada ukuran yang lebih pendek.

\section{KESIMPULAN DAN SARAN Kesimpulan}

1. Ikan kebogerang merupakan ikan omnivora yang memanfaatkan serangga, larva serangga sebagai makanan utama.

2. Ukuran pertama kali matang gonad 14,5 $\mathrm{cm}$ lebih pendek, yangdiduga karena tekanan lingkungan yaitu kualitas air yang buruk. 
3. Mempunyai fekunditas berkisar 3.47537.611 butir, diharapkan dapat berkembang biak secara berkelanjutan.

\section{Saran}

Berdasarkan

parameter reproduksinya, ikan di sungai Citarum sangat berpotensi untuk ditingkatkan produktifitas sumberdaya ikannya. Dengan program kali bersih mempertahankan lingkungan perairan agar kuaitas air sungai Citarum kembali baik untuk mendukung sumberdaya perikanan.

\section{UCAPAN DAN TERIMA KASIH}

Tulisan ini merupakan bagian dari kegiatan penelitian yang didanai APBN di Balai Penelitian Perikanan Perairan Umum Palembang Kajian Stok dan Sumberdaya Ikan di WPPNRI PD 433 Jawa Barat Tahun 2020. Ucapan terima kasih kami ucapkan kepada Ir. Siti Nurul Aida, MP yang telah membimbing penulis sehingga bisa menyelesaikan tulisan ini dengan baik.

\section{DAFTAR PUSTAKA}

Colia, R.C.Br.S., Efizon, D., dan Efawani. 2019. Analisis Isi Lambung Ikan Ingir-ingir (Mystus nigriceps Valenciannes) di Sungai Tarai Desa Tarai Bangun Kecamatan Tambang Kabupaten Kampar Provinsi Riau. Jurnal Online Mahasiswa (Jom) Universitas Riau: 1-13.

Edmonson, W.T. 1959. Freshwater Biology. Second Edition, John Willy and Sons, USA.

Effendie, M.I. 1979. Metode Biologi Perikanan. Yayasan Dewi Sri, Bogor. 122 Hal.

Effendie, M.I dan D.S. Sjafei. 1976. Potensi Produksi Ikan Belanak (Mugil dussumieri Valenciennes) di Perairan Muara Sungai Cimanuk lndramayu. LPPL No. 1 hal. 55-86
Effendie, M.I. 1997. Biologi Perikanan. Yayasan Pustaka Nusantara. Yogyakarta.

Gaffar, A. K dan A.D Utomo. 1991. Sumberdaya Perikanan Sungai Komering. Bull. Penel. Perikanan Darat 10 (3) : 1-6.

Hariyadi, S. 1983. Studi Makanan Alami Ikan-Ikan Mujair, Nila, Lele, Gabus, dan Mas di Situ Ciburuy, Kab. Bandung. Karya Ilmiah. Fak. Perikanan, IPB. 75 Hal (tidak dipublikasikan).

Heltonika1, B., Affandi, R., dan Supriatna, I. 2016. Pendugaan Ukuran Pertama Kali Matang Gonad Ikan Senggaringan (Mystus negriceps) di Sungai Klawing, Purbalingga Jawa Tengah. Jurnal Akuakultur Rawa Indonesia, 4(1):22-26

Kartamihardja, E.S. 2019. Degradasi Keanekaragaman Ikan Asli di Sungai Citarum, Jawa Barat. Warta Iktiologi Vol 3(2) November 2019: 1-8

Kottelat. M, A.J Whitten, S.N Kartikasari and S. Wirjoatmojo. 1993. Freshwater Fishes of Western Indonesia and Sulawesi. Periplus Editions (HK) Ltd bekerjasama dengan Proyek EMDI, Menteri Negara Kependudukan dan Lingkungan Hidup. Republik Indonesia. 293 hal.

Musbir, Achmar M, Sudirman dan Najamudin. 2006. Pendugaan Ukuran Pertama Kali Matang Gonad Ikan Kembung (Rastreliger kanagurta) di Perairan Laut Flores Sulawesi Selatan. J. Sains \& Teknologi. Vol 6 No 1 : 19-26.

Nataliska, Efizon, D., dan Efawani. 2019. Biologi Reproduksi Ikan Ingir-ingir (Mystus nigriceps) di Sungai Tarai Kabupaten Kampar Provinsi Riau. 
Jurnal Online Mahasiswa (Jom) Universitas Riau: 1-13.

Nikolsky , G.V, 1963. The Ecology of Fishes. Transleted by. L. Brikett. Academy Press. London.

Needham, J.G dan P.R Needham. 1969. Freshwater Biology. Holden. Day. Inc. San Francisco.
Tomkiewicz J, Morgan MJ, Burnett J, SaboridoRey F. 2003. Available information for estimating reproductive potential of Northwest Atlantic groundfish stocks. Journal of Northwest Atlantic Fishery Science, 33: 1-21. 